\title{
Analysis of Dielectric Properties On Agricultural Waste for Microwave Communication Application
}

\author{
Nurul Ain Zulkifli1 ${ }^{*}$, Fwen Hoon Wee ${ }^{1}$, Norfadila Mahrom ${ }^{1}$, Been Seok Yew ${ }^{1}$, Yeng Seng Lee ${ }^{1}$, Siti Zuraidah Ibrahim $^{1}$, \\ Anusha Leemsuthep Am Phan ${ }^{1 .}$ \\ ${ }^{1}$ Bioelectromagnetic (BioEM), School of Computer and Communication Engineering, Universiti Malaysia Perlis, Arau, Perlis, Malaysia.
}

\begin{abstract}
This paper presents the analysis of dielectric properties of agricultural waste for microwave communication application such as microwave absorber and antenna. The residues products - rice straw, rice husk, banana leaves and sugar cane bagasse were studied in the range between 1-20GHz. Firstly, the 2 types of resins namely Epoxy der 331 and Polyamine clear hardener were mixed with the agricultural waste materials to produce the small size of agricultural waste sample. Then, the sample were measured using PNA network analyzer. The permittivity and tangent loss of different agricultural waste samples have been measured using dielectric probe technique. Besides, other objectives of this paper is to replace the conventional printed circuit board (PCB) using FR4, Taconic, and Roger material with the agricultural waste material. Besides that, the different percentage of filer for each agricultural waste materials were also investigated to specify the best material to be used as the substrate board and as the resonant material. the result shows the average of dielectric constants and the average of the tangent loss of agricultural waste materials.
\end{abstract}

\section{Introduction}

Dielectric properties measurement of agricultural waste materials is the main factor in defining the chemical-physical properties characterization associated to store and loss of energy [1]. Equation (1) shows the formula for permittivity (dielectric constant).

$$
K=\frac{\varepsilon}{\varepsilon_{o}}=\varepsilon_{r}=\varepsilon_{r}^{\prime}-j \varepsilon_{r}^{\prime \prime}
$$

Permittivity is known as dielectric constant of a material. the dielectric constant $\mathrm{K}$ is equal to the relative permittivity $\varepsilon_{r}$. Relative permittivity of a material refers to the $\varepsilon_{r}^{\prime}$ as the real part of dielectric constant and $\mathrm{j} \varepsilon^{\prime \prime}{ }_{r}$ known as the imaginary part of permittivity. The energy storage capability in a material is known as $\varepsilon^{\prime}{ }_{r}$ while $\varepsilon^{\prime \prime}{ }_{r}$ is familiar with the loss factor of a material [1-4].

Loss tangent measurement is another parameter used in determine the dielectric properties of a material. The formula of loss tangent is shown in equation (2) below. The relative "loss" of a material is the ratio of the energy lost $\varepsilon^{\prime \prime}{ }_{r}$ to the energy stored $\varepsilon^{\prime}{ }_{r}$ [5-7].

$$
\delta \tan =\frac{\varepsilon^{\prime \prime}{ }_{r}}{\varepsilon_{r}^{\prime}}
$$

Agricultural wastes are made up of organic compounds from living plants. Sugarcane bagasse [6, 8], rice husk [7], rice straw, and banana leaves [5], [9-11] are the residues products used in this work. These materials have potential to be used as an alternative material for microwave communication applications like antenna and microwave absorber. The high reading of dielectric constant of a material are suitable for antenna application while the high reading of loss tangent is suitable for microwave absorber used in anechoic chamber.

Agricultural waste material can be used as an alternative for microwave absorber application, antenna application, and for replacement the conventional printed circuit board (PCB).

Table 1 shows the percentage chemical elements of Agricultural waste materials. From the table, it shows that rice husk [12], banana leaves [13] and sugarcane bagasse [14] are suitable for microwave absorber application due to the high amount of carbon content. Oxygen content of sugarcane bagasse shows the highest reading among the other agricultural waste. This is the reason why the sugarcane bagasse is lighter in weight compared to others. Silica amount in agricultural waste material helps to reduce the loss tangent of a material. Low loss tangent of a material is suitable for antenna application. 
Table 1. Percentage chemical elements of agricultural waste material

\begin{tabular}{|l|c|c|c|}
\hline \multirow{2}{*}{ Elements } & \multicolumn{3}{|c|}{ Percentage Elements } \\
\cline { 2 - 4 } & $\begin{array}{c}\text { Rice } \\
\text { Husk }\end{array}$ & $\begin{array}{c}\text { Banana } \\
\text { Leaves }\end{array}$ & $\begin{array}{c}\text { Sugarcane } \\
\text { Bagasse }\end{array}$ \\
\hline Carbon & $35.77 \%$ & $43.5 \%$ & $17.89 \%$ \\
\hline Hydrogen & $5.06 \%$ & $6.28 \%$ & - \\
\hline Nitrogen & $0.32 \%$ & $1.31 \%$ & - \\
\hline Sulphur & $0.02 \%$ & $0.36 \%$ & $0.07 \%$ \\
\hline Oxygen & & $41.3 \%$ & $75.6 \%$ \\
\hline $\begin{array}{l}\text { Silicon } \\
\text { dioxide }\end{array}$ & $22.24 \%$ & - & - \\
\hline Aluminium & - & - & $1.47 \%$ \\
\hline Silica & - & - & $2.67 \%$ \\
\hline Phosphorus & - & - & $0.75 \%$ \\
\hline Potassium & - & - & $0.04 \%$ \\
\hline Calcium & - & - & $0.58 \%$ \\
\hline Iron & - & - & $0.4 \%$ \\
\hline
\end{tabular}

\section{Method Used}

This project is classified into 5 phases consisting collecting, grinding, mixing, sampling and analysing.

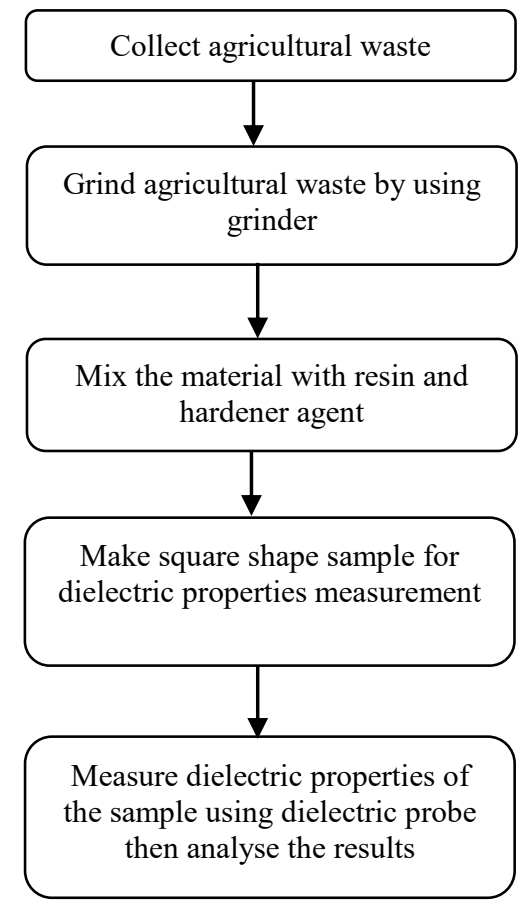

Fig. 1. steps of developing the sample of agricultural waste.
Figure 1 shows the steps for this projects. Firstly, the raw material for this project is collected. The agricultural waste that has been chosen are rice husk, rice straw, sugar cane bagasse and banana leaves. Rice husk and rice straw are collected from Kilang Beras BERNAS, Kuala Perlis, Perlis.

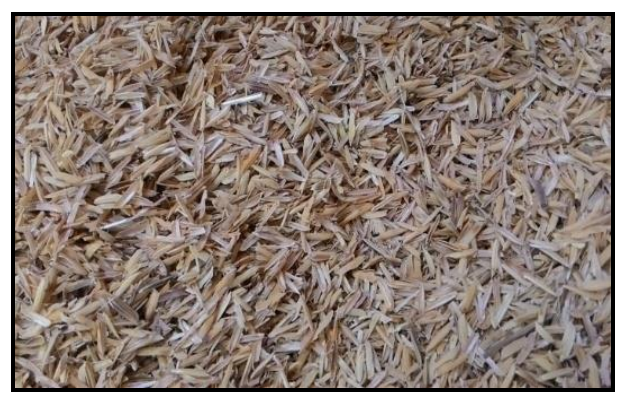

(a)

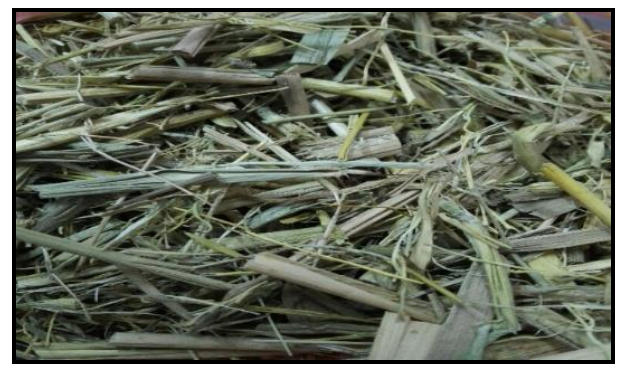

(b)

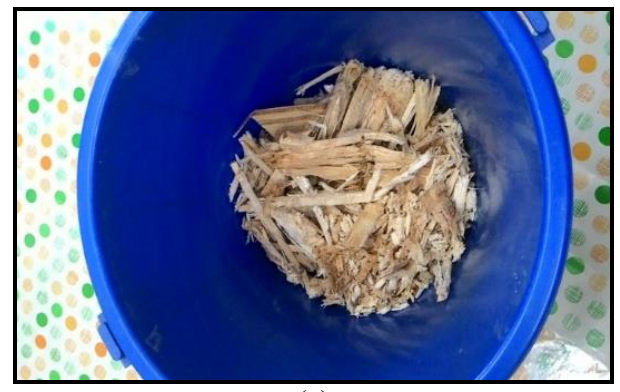

(c)

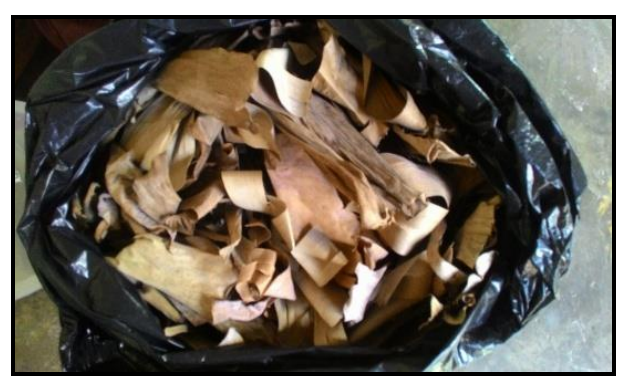

(d)

Fig. 2. Raw material of agricultural waste. a) rice husk. b) rice straw. c) sugarcane bagasse. d) dried banana leaves

Then, all the raw materials as shown in figure 2 have to grind by using grinder to get small particles. This is to make sure that all the materials can easily stick together with the chemical used. Figure 3 shows the image of grinder. 


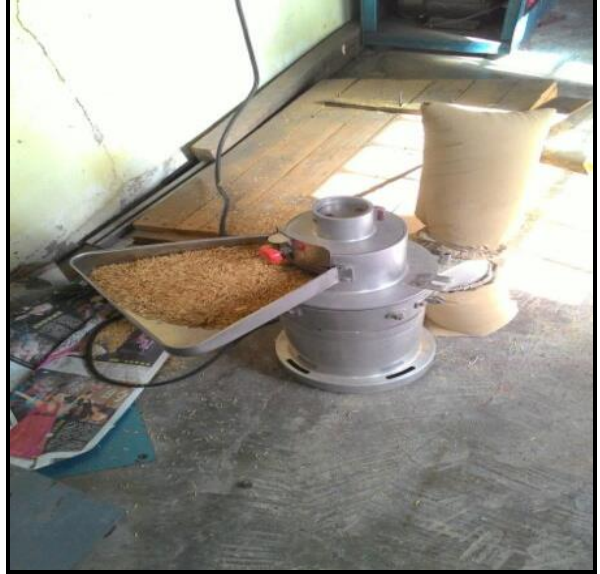

Fig. 3. Image of grinder

After that, all the materials were mixed together with the resin namely Epoxy Der 331. Resin is usually used as a glue for bonding the materials. Then to make the sample become solid, Polyamine Clear Hardener is added into the mixture. Five different sample of $10 \%$, $20 \%, 30 \%, 40 \%$, and $50 \%$ of filler for each materials is needed for this project. The mixture is required to be stirred evenly for more than 5 minutes to avoid air gap. Figure 4 shows the mixture is being stirred by using wood skewer stick. Next, figure 5 shows the mixture is then put in a rectangular mould to get the desired shape. Then, it will be left for two or three days in room temperature to ensure the mixture become hardened.

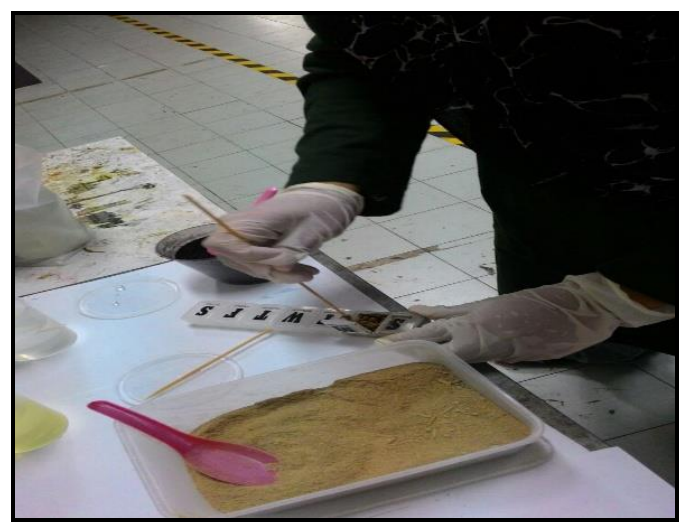

Fig. 4. Mixture is stirred using stick

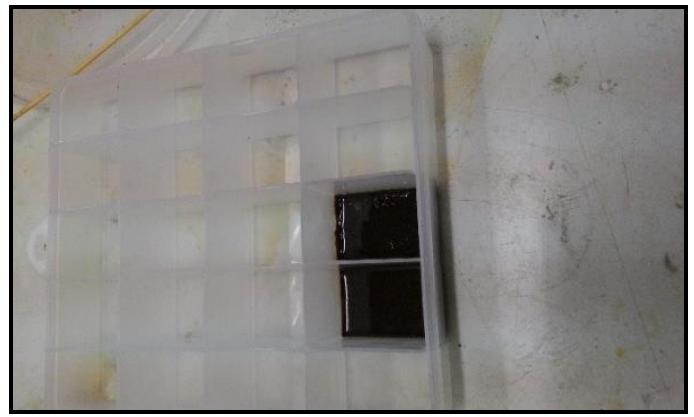

Fig. 5. Rectangular mould
The analysis of dielectric properties will be take place after two days of moulding the mixture. This is to ensure that it is moulded firmly before proceeding to any processes. Figure 6 shows the sample of each agricultural waste material after taken out from the square mould.

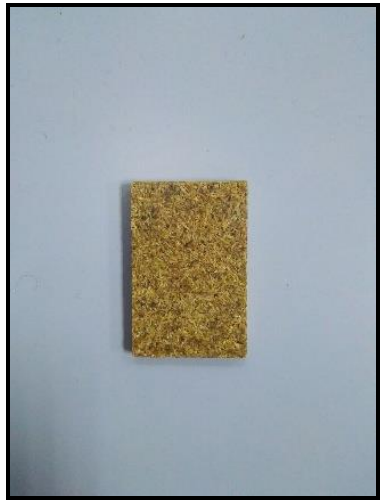

(a)

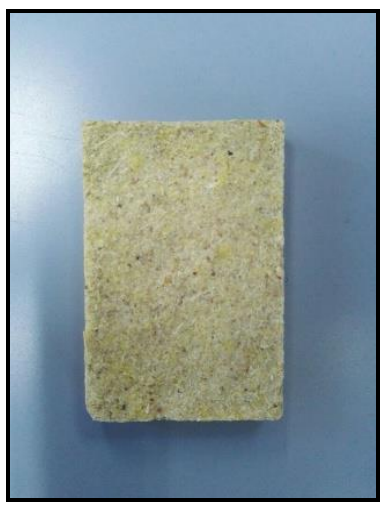

(c)

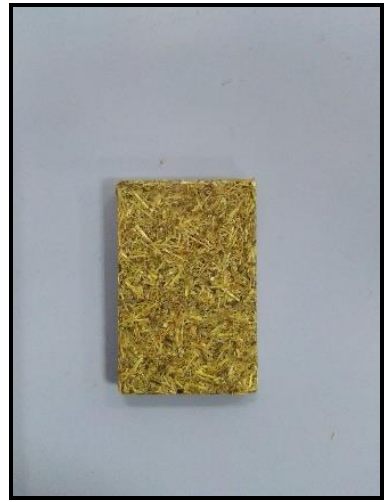

(b)

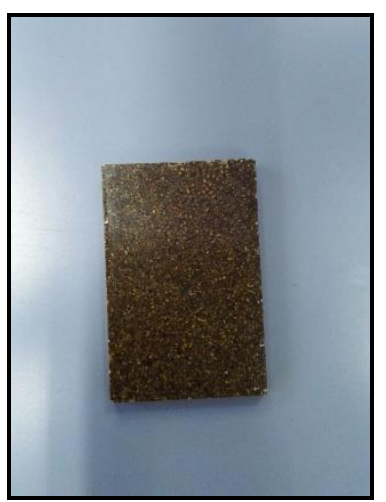

(d)
Fig. 6. Sample of (a) rice straw. (b) rice husk. (c) sugarcane bagasse. (d) banana leaves.

Figure 7 shows the Agilent dielectric probe technique that is used to analyse the dielectric properties of the material. This technique used Agilent Technologies 85070 measurement software. Before measuring the dielectric properties for each material, calibration is needed to avoid the error occurred during the measurement. Figure 8 shows the calibration tools for dielectric probe.

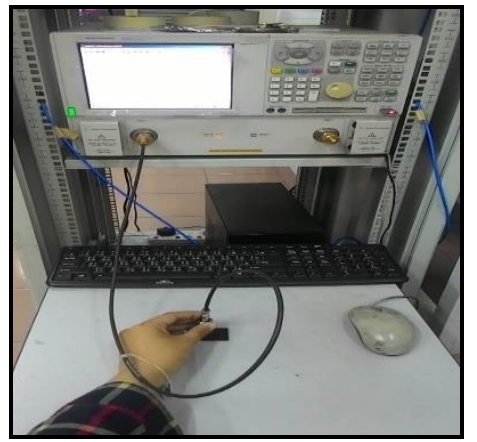

Fig. 7. Dielectric probe technique 


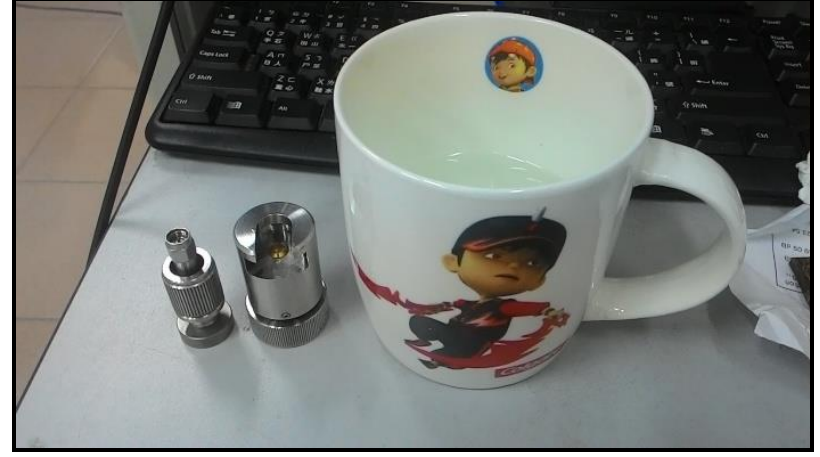

Fig. 8. Calibration tools

\section{Results and Discussion}

Table 2 shows the comparison of dielectric constant between various percentage of rice husk, rice straw, sugarcane bagasse and banana leaves. The reading of dielectric properties is taken by using dielectric probe measurement technique[6]. In addition, table 3 shows the results of loss tangent with percentage $10 \%, 20 \%, 30 \%$, $40 \%$ and $50 \%$ for four different agricultural waste. The overall results indicate that the higher the percentage of filler, the higher reading of dielectric constant and loss tangent. From the table 2 and 3, it shows that banana leaves are the best in term of the results of dielectric properties compared with other three agricultural waste sample. The results of dielectric constant and loss tangent show the unstable reading for rice husk, rice straw, and sugarcane bagasse.

Table 2. Average dielectric constant of different material with different percentage of filler.

\begin{tabular}{|l|l|l|l|l|l|}
\hline \multirow{2}{*}{$\begin{array}{l}\text { Agricultural } \\
\text { waste }\end{array}$} & \multicolumn{5}{|c|}{$\begin{array}{c}\text { Dielectric constant with different } \\
\text { percentage of filler }\end{array}$} \\
\cline { 2 - 6 } & $\mathbf{1 0 \%}$ & $\mathbf{2 0 \%}$ & $\mathbf{3 0 \%}$ & $\mathbf{4 0 \%}$ & $\mathbf{5 0 \%}$ \\
\hline Rice husk & 3.796 & 3.909 & 3.873 & 4.134 & 3.394 \\
\hline Rice straw & 3.042 & 3.585 & 3.789 & 3.431 & 3.231 \\
\hline $\begin{array}{l}\text { Sugarcane } \\
\text { bagasse }\end{array}$ & 3.447 & 3.736 & 3.422 & 3.078 & 2.791 \\
\hline $\begin{array}{l}\text { Banana } \\
\text { leaves }\end{array}$ & 3.143 & 3.243 & 3.374 & 3.756 & 4.221 \\
\hline
\end{tabular}

From the results in table 2, it shows that banana leaves with $50 \%$ of filler has the highest reading of dielectric constant. Hence, this result is suitable for antenna application. Furthermore, the overall analysis with $10 \%$ of filler for different agricultural waste material shows the reading of loss tangent is less than 0.1 . This results are acceptable for antenna application due to the low loss tangent and high reading of dielectric constant. The general reading of $40 \%$ of filler for loss tangent for different agricultural waste is high compared with other percentage. Since the reading of loss tangent is high, so that the sample of different agricultural waste sample for $40 \%$ of filler has potential to be used as an alternative material for microwave absorber application. Microwave absorber application is used in Radio Frequency (RF) anechoic chamber.

Table 3. Average loss tangent of different material with different percentage of filler.

\begin{tabular}{|l|l|l|l|l|l|}
\hline \multirow{2}{*}{$\begin{array}{l}\text { Agricultural } \\
\text { waste }\end{array}$} & \multicolumn{5}{|c|}{ Loss tangent with different percentage of } \\
& \multicolumn{5}{|c|}{ filler } \\
\cline { 2 - 6 } & $\mathbf{1 0 \%}$ & $\mathbf{2 0 \%}$ & $\mathbf{3 0 \%}$ & $\mathbf{4 0 \%}$ & $\mathbf{5 0 \%}$ \\
\hline Rice husk & 0.099 & 0.107 & 0.112 & 0.137 & 0.133 \\
\hline Rice straw & 0.086 & 0.107 & 0.121 & 0.139 & 0.119 \\
\hline $\begin{array}{l}\text { Sugarcane } \\
\text { bagasse }\end{array}$ & 0.094 & 0.105 & 0.125 & 0.135 & 0.129 \\
\hline $\begin{array}{l}\text { Banana } \\
\text { leaves }\end{array}$ & 0.095 & 0.103 & 0.114 & 0.132 & 0.149 \\
\hline
\end{tabular}

\section{Conclusion}

The investigation showed that different percentage of filler will give the different dielectric constant and different tangent loss performance. The variety type of agricultural waste material also brings it to different dielectric properties performance. Besides that, the high reading of dielectric constant is suitable for antenna application while the high reading of loss tangent is acceptable for microwave absorber application. The cost of the microwave absorber and other microwave communication application can be reduced by using agricultural waste as the main materials. This agricultural waste material is cheaper compared to the conventional materials. The existing materials for high frequency is expensive and not guarantee its performance and effectiveness. Lastly, the main material 
for the commercial antenna and absorbers are not environmental friendly due to the usage of $100 \%$ base chemical materials. Therefore, the usage of agricultural waste material is introduced to replace the conventional material to avoid the use of harmful chemicals and at the same time support the campaign of green technology.

\section{Acknowledgement}

The author would like to thank the Ministry of Higher Education of Malaysia (MOHE) for the financial support for this research work in terms of FRGS grant of 9003-00591.

\section{References}

[1] F. H. Wee, P. J. Soh, a. H. M. Suhaizal, H. Nornikman, and A. a. M. Ezanuddin, Microw. Optoelectron. Conf. (IMOC), 2009 SBMO/IEEE MTT-S Int., no. I, pp. 183-187, 2009.

[2] A. Kundu and B. Gupta, Int. Conf. Control. Instrumentation, Energy Commun. CIEC 2014, no. 1980, pp. 480-484, 2014.

[3] O. V Tereshchenko, F. J. K. Buesink, and F. B. J. Leferink, pp. 1-4, 2011.

[4] W. F. Hoon, S. P. Jack, M. F. A. Malek, and N. Hassan, Sci. Technol. Med. open access Publ., no. March 2017, pp. 91-112, 2012.

[5] R. Kaur, G. D. Aul, and V. Chawla, Prog. Electromagn. Res. $M$, vol. 43, no. July, pp. 157164, 2015.

[6] Z. Liyana et al., IEEE Symp. Wirel. Technol. Appl. ISWTA, pp. 66-70, 2012.

[7] H. Nornikman, P. . Soh, a a H. Azremi, F. H. Wee, and M. F. Malek, Piers Online, vol. 5, pp. 506-510, 2009.

[8] K. Ho, no. December, pp. 1-13, 2006.

[9] Z. S. Farhany et al., IEEE Symp. Wirel. Technol. Appl. ISWTA, pp. 60-65, 2012.

[10] V. D. Kappel, L. H. Cazarolli, D. F. Pereira, F. H. Reginatto, and F. R. M. B. Silva, Rev. Bras. Farmacogn. - BrazilianJournal Pharmacogn., vol. 23, no. 4, pp. 706-715, 2013.

[11] E. R. K. Fernandes, C. Marangoni, S. H. W. Medeiros, O. Souza, N. Sellin, and Z. Industrial, 3rd Int. Conf. Ind. Hazard. waste Manag., pp. 18, 2012.

[12] H. Nornikman, F. Malek, P. J. Soh, A. A. H. Azremi, F. H. Wee, and A. Hasnain, Prog. Electromagn. Res., vol. 104, pp. 145-166, 2010.

[13] J. Y. Tock, C. L. Lai, K. T. Lee, K. T. Tan, and S. Bhatia, vol. 14, pp. 798-805, 2010.

[14] P. B. Devnarain, D. R. Arnold, and S. B. Davis, Congr. South African Sugar Technol. Assoc., pp. 477-489, 2002. 